\title{
The non-random distribution of copper within the liver of rats
}

\author{
BY S. HAYWOOD \\ Department of Veterinary Pathology, University of Liverpool L69 3BX
}

(Received 28 March 1980 - Accepted 9 June 1980)

\begin{abstract}
1. Two groups of weanling male rats were fed on a powdered proprietary diet for up to 6 weeks. The diet of one group was supplemented with $2 \mathrm{~g} \mathrm{Cu} / \mathrm{kg}$ and the other group received the unsupplemented diet.

2. The livers in the supplemented group accumulated more $\mathrm{Cu}$ within the right vascular compartment than the left. This difference was observed in the unsupplemented group after 6 weeks but not at 4 weeks.

3. The distribution of $\mathrm{Cu}$ between the different lobes of the livers of the supplemented groups displayed a characteristic pattern, the median lobe containing the most $\mathrm{Cu}$ and the omental lobe the least.

4. The distribution of $\mathrm{Cu}$ within the liver is thought to reflect the site of its absorption from the gastointestinal tract and a consequence of portal streaming.
\end{abstract}

Uneven distribution of copper throughout the liver of several animal species was first observed in the investigation of normal $\mathrm{Cu}$ levels (Beck, 1956). Other workers have since reported similar variations in the livers of several domesticated animal species (Cuill et al. 1970; Bingley \& Dufty, 1972). In an experiment designed to study the anatomical distribution of $\mathrm{Cu}$ in both normal and tumour bearing rats on a $\mathrm{Cu}$ supplemented diet Howell (1959) noticed that the histological distribution of $\mathrm{Cu}$ varied between the different lobes, there being more $\mathrm{Cu}$ in the median lobes. When a $\mathrm{Cu}$-supplemented diet was fed to rats (Haywood, 1980) it was found that the lesions induced as a consequence of this were consistently more severe in the peripheral parts of the median and right lobes than in the other lobes. It was surmized that this was possibly due to the greater accumulation of $\mathrm{Cu}$ in these lobes and it was decided to investigate this further.

\section{MATERIALS AND METHODS}

Twenty-four 4-week-old weanling male rats of approximately $100 \mathrm{~g}$ in weight were allocated randomly to two groups of sixteen and eight animals and housed four per cage. The larger group received a powdered rodent diet (Spillers expanded rodent diet; $7 \mathrm{mg} \mathrm{Cu} / \mathrm{kg}$ ) to which $2 \mathrm{~g} \mathrm{Cu} / \mathrm{kg}\left(\mathrm{CuSO}_{4}\right)$ had been added and the smaller group received the unsupplemented diet. Food and water were supplied ad lib.

Half the animals in each group were killed after 4 weeks ( 8 weeks of age) and the remainder after 6 weeks ( 10 weeks of age). Their livers were removed and divided each into six parts (parts nos. 1-6; Fig. 1). The larger lobes were again each subdivided into smaller blocks ( $a$ and b; Fig. 1). Each liver came to consist of ten blocks which were subsequently analysed for their $\mathrm{Cu}$ content. Small $(0.5-1.0 \mathrm{~g})$ portions were first dried and then digested in triplicate in a mixture of nitric-perchloric-sulphuric acids $(3: 1: 1, \mathrm{v} / \mathrm{v})$ and the $\mathrm{Cu}$ content measured by atomic absorption spectrophotometry. The liver $\mathrm{Cu}$ concentrations were expressed as $\mu \mathrm{g} / \mathrm{g}$ dry weight. The $\mathrm{Cu}$ content in different lobes and within different parts of the same lobe were compared and the differences assessed for their significance by Student's $t$ test. In addition the Cu content of the left compartment of the liver (omental and left lobes) was compared with the $\mathrm{Cu}$ content in the right compartment (median, right and caudate lobes) as designated from the vascular territories outlined by Himsworth (1950) whereby the left part of the liver receives venous blood from the stomach and spleen and the right part receives venous blood from the intestines. 


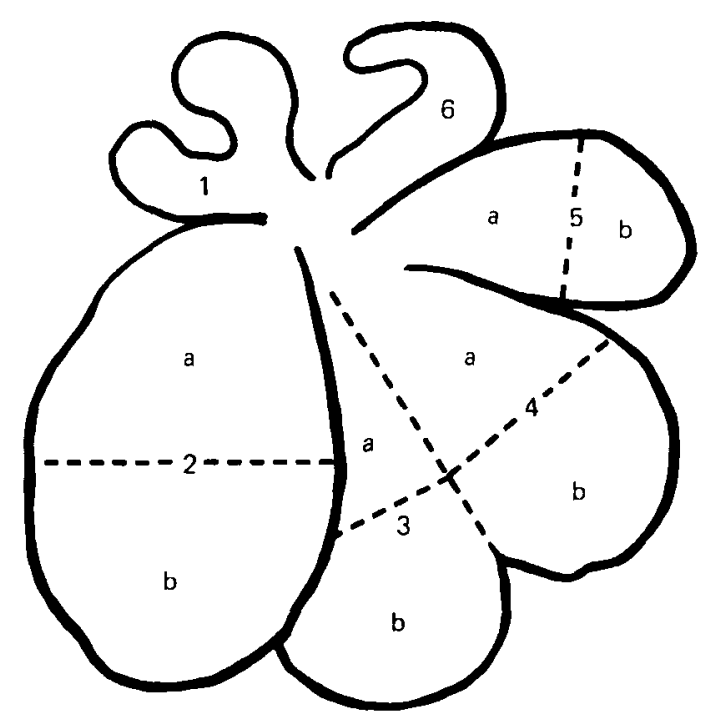

Fig. 1. Dorsal view of rat liver with lobes displayed. 1, omental lobe; 2 , left lobe; 3 and 4 , left and right parts of median lobe respectively; 5 , right lobe; 6 , caudate lobe; $(--)$ line of section.

\section{RESULTS}

When liver $\mathrm{Cu}$ concentrations were compared at 4 weeks, it was found that, in the unsupplemented group, there was no significant difference in $\mathrm{Cu}$ content $(P>0.05)$ between or within individual lobes, neither did the $\mathrm{Cu}$ concentration when considered over all in the left compartment differ from that in the right compartment $(P>0.05)$ (Table 1). In the supplemented group, however, there was a concentration gradient of $\mathrm{Cu}$ which achieved a maximum in the right median lobe falling off on either side (Fig. 2) and the right compartment contained significantly more $\mathrm{Cu}$ than the left compartment $(P<0.001)$. There was no significant difference in $\mathrm{Cu}$ content within individual lobes.

In the unsupplemented groups at 6 weeks, there was more $\mathrm{Cu}$ in the right compartment than the left $(P<0.001)$ (Table 2$)$; most $\mathrm{Cu}$ being in the left median lobe, the values falling off on either side. In the supplemented groups the $\mathrm{Cu}$ concentration gradient between the different lobes was even more marked than at 4 weeks, achieving a maximum in the median lobes and falling off on either side as before (Fig. 2). The difference in $\mathrm{Cu}$ content between the median and other lobes was in all instances highly significant $(P<0.001)$ and the over-all difference in content between the right and left compartments was again highly significant $(P<0.001)$. There was no significant difference in $\mathrm{Cu}$ concentration within individual lobes.

\section{DISCUSSION}

The right compartment of the rat liver showed a tendency to accumulate more $\mathrm{Cu}$ than the left. This was particularly marked in those animals that received $\mathrm{Cu}$-supplemented diets but was also apparent in animals fed on a standard diet for more than 4 weeks. In addition the animals receiving $\mathrm{Cu}$ supplementation showed a distinct pattern of $\mathrm{Cu}$ distribution within the liver there being most in the median lobes, then in the right, left, caudate and omental lobes respectively.

In dogs dye-injection studies have shown that there is incomplete mixing of blood in the portal vein and that consequently blood from the intestine passes mainly into the right lobes whereas that from the stomach and spleen passes mainly into the left lobes (Copher \& Dick, 


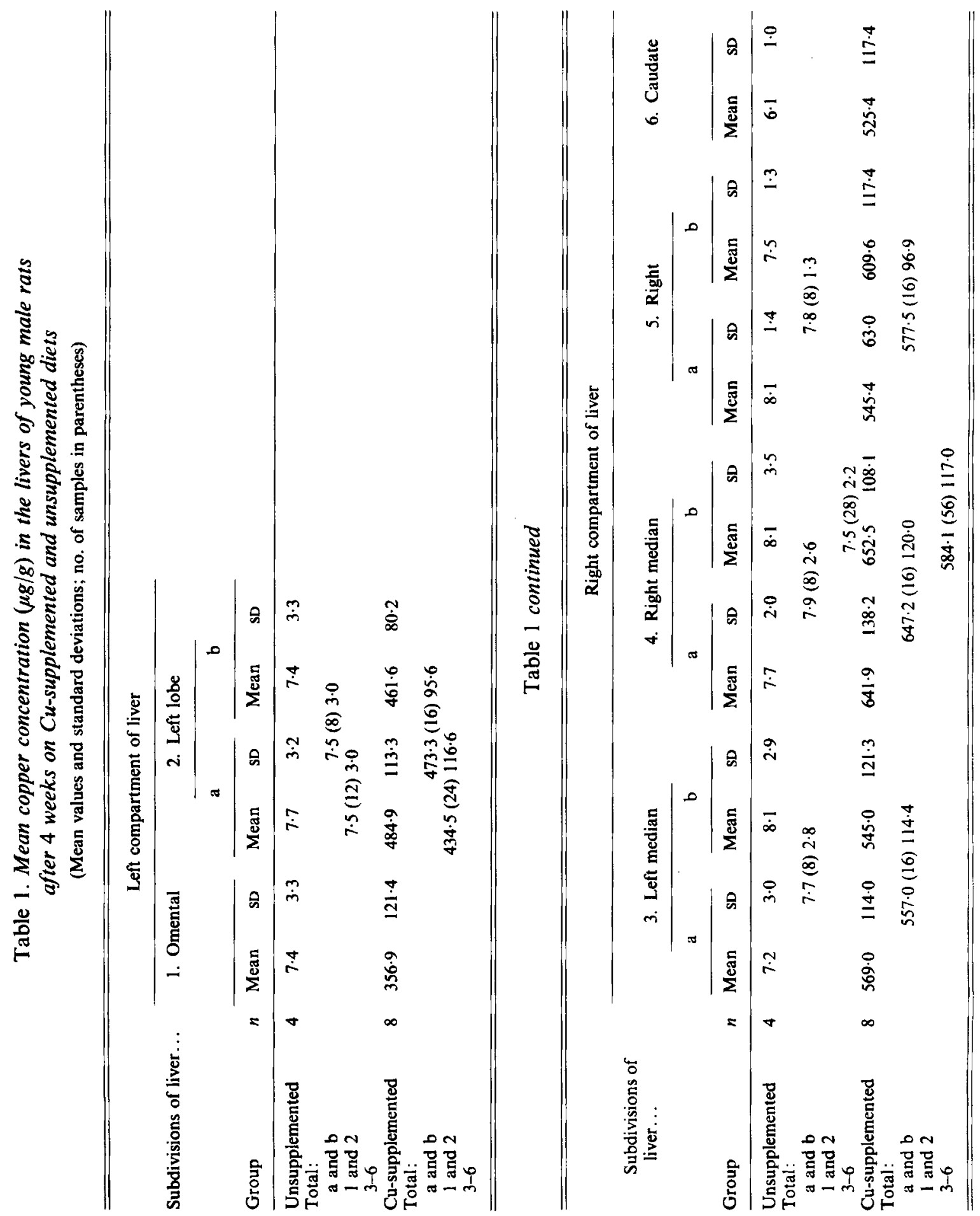




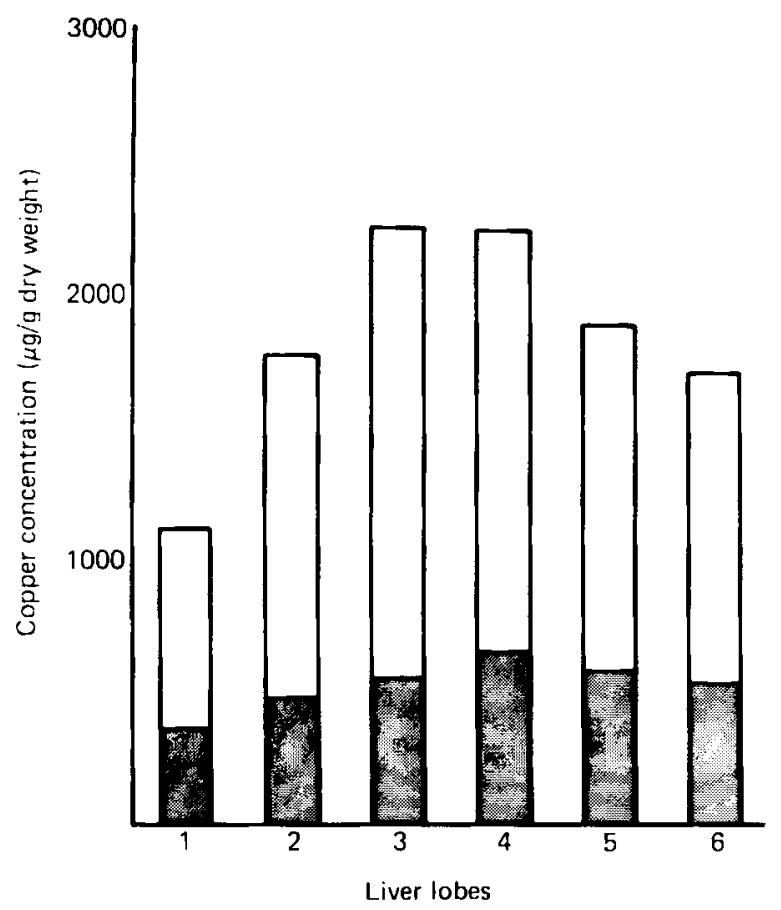

Fig. 2. Copper concentration $(\mu \mathrm{g} / \mathrm{g}$ dry weight) within liver lobes, nos. 1-6 after feeding a Cu-supplemented diet for 4 weeks $(\square)$ and 6 weeks $(\square)$.

1928). Himsworth (1950) demonstrated a similar streaming effect in the rat: venous blood from the gastro-splenic region entered the left and omental lobes and that from the mesenteric vein passed into the other lobes of the liver. This gave rise to the concept of vascular territories or compartments.

It follows from this that substances absorbed from the gastrointestinal tract would be delivered to either the right or left compartment depending upon the site of absorption. There is some difference of opinion regarding the site of absorption of $\mathrm{Cu}$. Van Campen \& Mitchell (1965) ligated different portions of the alimentary tract in rats and measured the absorption of $\mathrm{Cu}$ into the blood from each ligated segment. They found that absorption was greatest from the stomach followed by the duodenum, jejunum, ileum in descending order. This cannot be taken to represent the state of affairs in the intact animal since the length of time normally spent by food in any one portion of the alimentary tract was not taken into consideration.

In an experiment which approximated more to normal conditions Owen (1964) injected $\mathrm{Cu}$ salts into various parts of the gastrointestinal tract of intact rats and measured absorption indirectly by means of faecal $\mathrm{Cu}$ output. By these means he found that, although gastric absorption was considerable, the greater proportion of $\mathrm{Cu}$ absorption occurred from the intestine with maximal absorption taking place from the upper part of the jejunum. This would provide a satisfactory explanation for the observations recorded in this study. It is likely that $\mathrm{Cu}$ absorbed from the stomach and from the duodenum is deposited in the omental and left lobes, that from the jejunum accumulates in the median lobe and that absorbed from the lower small intestine passes into first the right and then the caudate lobe; decreasing absorption represented by the falling values. The concept that hepatic deposition of an absorbed substance reflects accurately the site of its absorption derives from that of 


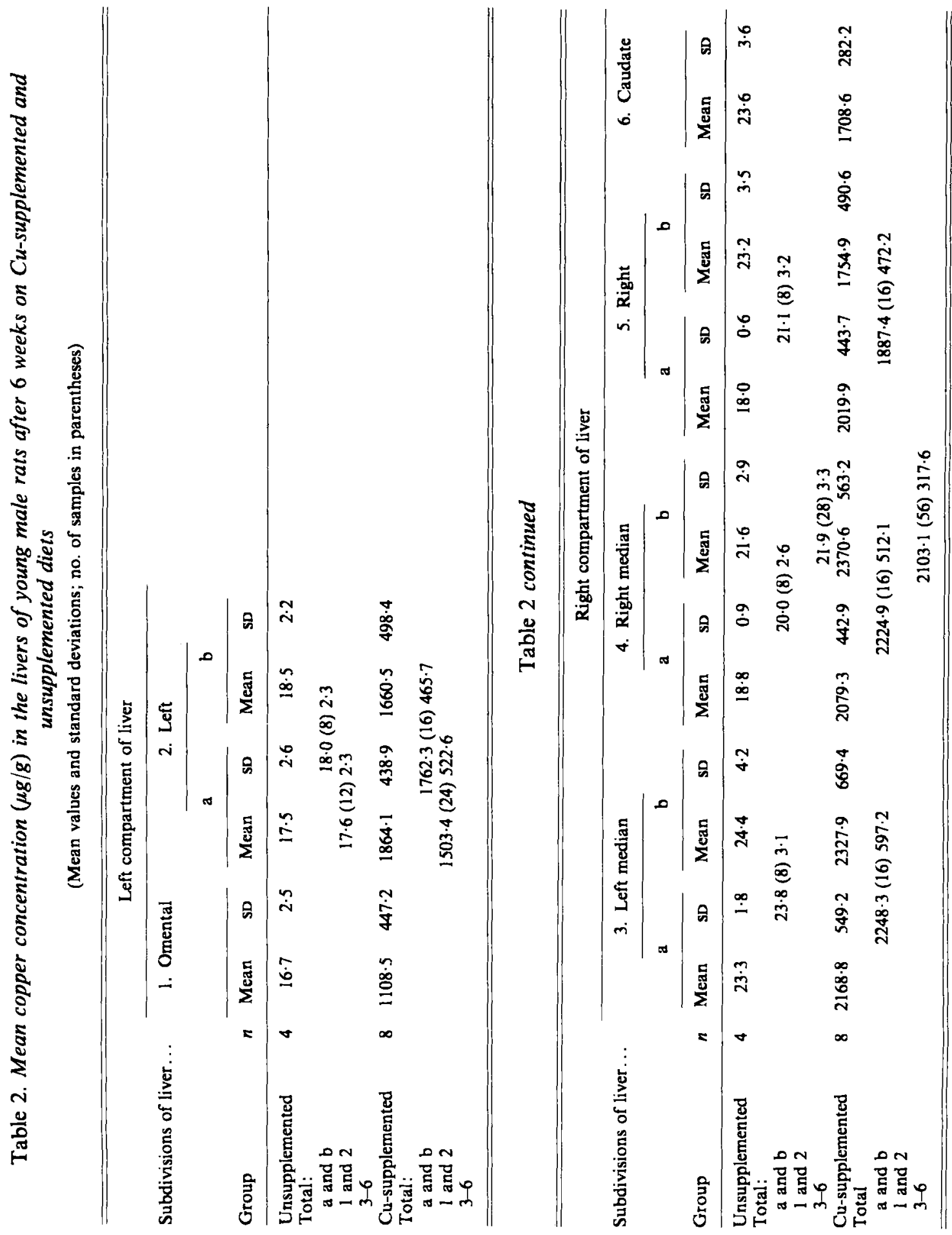


portal streaming and may apply to nutrients generally as well as to potentially toxic agents. There may well be functional differentiation within different anatomical lobes of the liver with regard to the metabolism of nutrients and toxic agents. The greater accumulation of $\mathrm{Cu}$ in the median lobes certainly explains the greater severity of the lesions in that lobe in $\mathrm{Cu}$ toxicity (Haywood, 1980) although there is as yet no explanation for the mainly peripheral localization of such lesions as there is no variation in $\mathrm{Cu}$ content between the hilar and peripheral parts of individual lobes. The difference in distribution of $\mathrm{Cu}$ within the liver has practical applications too in that care should be taken in relying on the $\mathrm{Cu}$ content of a small sample of liver (a biopsy for example) as an indication of total liver content.

There was no difference of $\mathrm{Cu}$ deposition in the livers of the unsupplemented group after only 4 weeks. $\mathrm{Cu}$ is present in high concentrations in the neonatal rat liver; as it is derived from the mother in utero it is presumably evenly distributed throughout the liver and must serve as a reserve for the requirements of the first few weeks of life. After weaning $\mathrm{Cu}$ is absorbed from the food and presumably it takes some time for the selective distribution to become apparent.

Finally it is possible that the differences in distribution reflect differences in biliary excretion of $\mathrm{Cu}$ rather than its absorption. However there is as yet no evidence of any variation in bile secretion within the normal liver.

The author wishes to thank Professor D. F. Kelly for his helpful advice, Mr Barry Comerford for technical assistance with the copper analyses and Mrs Paula Jenkins for the illustrations.

\section{REFERENCES}

Beck, A. B. (1956). Aus. J. Zool. 4, 1.

Bingley, J. B. \& Dufty, J. H. (1972). Res. Vet. Sci. 13, 8.

Copher, G. H. \& Dick, M. B. (1928). Archs Surg., Lond. 17, 405

Cuill, T. O., Hamilton, A. F. \& Egan, D. A. (1970). Ir. Vet. J. 24, 21.

Haywood, S. (1980). J. comp. Path. 90, 217.

Himsworth, H. P. (1950). Lectures on the Liver and its Diseases. Oxford: Blackwell Scientific Publications.

Howell, J. S. (1959). J. Path. Bact. 77, 474.

Owen, C. A. (1964). Am. J. Physiol. $207,1203$.

Van Campen, D. R. \& Mitchell, E. A. (1965). J. Nutr. 86, 120. 